\title{
Social Mobilization in District Mardan; Human Development Foundation
}

\author{
Muhammad Azam¹, Shaista Naz ${ }^{1}$, Muhammad ilyas ${ }^{2 *}$, Asadullah² and Waqas khan ${ }^{2}$ \\ ${ }^{1}$ Department of Rural Development Faculty of Rural Social Sciences, The University of Agriculture Peshawar, Pakistan \\ ${ }^{2}$ Department of Horticulture, The University of Agriculture Peshawar, Pakistan
}

Submission: November 17, 2017; Published: January 09, 2017

*Corresponding author: Muhammad Ilyas, Department of Horticulture, The University of Agriculture Peshawar, Pakistan, Email: Azamkhan2090.ak@gmail.com

\begin{abstract}
The research was carried on Human Development Foundation (HDF) with the objectives to study its work environment, and its main activities of Social Mobilization(SM) programme in district Mardan of Khyber Pakhtunkhwa. SM programme is operating in 79 villages of the district since 1999. The objective of the SM is to develop social capital and prepare the communities to undertake sustainable development initiatives by making VDOs including all segments of the society through Participatory Rural Approach. Findings of the programme revealed that 45 VDOs were in grade " $\mathrm{A}$ ", 9 in grade "B" and 25 were in grade " $\mathrm{C}$ ". The grading were needed on the basis of well up in the measuring indicates. Grade A was comparatively more well up than Grade B and Grade B was more well up than Grade C. Performance indicators including education, health, economic development, community physical infrastructure and social capital. Furthermore, the programme is operating since long in the district but did not achieve the sufficient required results due to insufficient male and female staff and community perceptions about tangible work which should be overcome by increasing the number of staff and creating more awareness among the communities about the programme.
\end{abstract}

Keywords: Mobilization; Mardan; Foundation; District

\section{Introduction}

The success of the rural development depends upon the active participation and willing co-operation of the rural people through self-help organizations and voluntary agencies. In recent years, the voluntary agencies have acquired greater importance and significance than before because the administration has not been able to reach the people, especially the poor and weaker sections. They have been able to make their presence felt from the local to the national level and now at the international level also. Many of them have pioneered works in areas, which were ignored by the process of national development planning [1] of late, great success has been achieved around the world in programmes like immunization, eradicating illiteracy; empowerment of the weak and the underprivileged, creating self-managed institutions of the poor etc. One of the key elements responsible for this success has been the concept of social mobilization, the process of bringing together all feasible and practical inter-sectoral social allies to raise people's awareness of and demand for a particular development programme, to assist in the delivery of resources and services and to strengthen community participation for sustainable and self-reliance [2]. Social mobilization is about empowering the poor based on three vital parameters of power i.e; having their own capital, their own knowledge and their own organizations [2]. Its idea of empowerment is based on the assumption that there are three fundamental sources of power that is:

a. Capital is power and for self-reliance, the habit of saving must be included

b. Knowledge is power; no development can be sustained without the process being grounded in one's own knowledge base, culture and skills.

c. Organization is power for participation to be effective and dynamic; the groups must respect the principle of social, economic and cultural homogeneity.

There is a symbiotic relationship between social mobilization and development process. Social mobilization lies at the genuine development. It gives impetus to the necessary changes that must occur before development whether social, political or economic-can be realized [3]. Social Mobilization is the process of dialogue, negotiation and consensus building for action by people, communities, and organizations etc. to identify, address and solve a common problem [4]. It can be an effective strategy to create the kind of supportive environment necessary to create sustained behavioral change that will bring about community participation for sustainability and selfreliance. To achieve this according to [4], the strategy must reach 
from the highest levels of societal power to the hardest to reach and the most disempowered families and community. Social mobilization is methodologies for making the poor contribute to economic growth [5], is of the opinion that "social mobilization provides a non-violent way of the morass of deprivation, alienation, insecurity, political graft, and corruption experienced relentlessly over the past fifty years of development and democracy". Social mobilization is commonly considered to be an important dimension of capacity, organization and institution building, particularly, when relating to disadvantaged people. Social mobilization may occur at all levels. Most often, however, the term is used for activities in local communities, although not necessarily confined to such communities. When thus confined, the process is commonly referred to as community mobilization. This may involve whole communities or be limited to sections of communities. Community members can maximize their potential not only by organizing themselves but also by upgrading their existing skills to better manage new inputsbusiness and community initiatives and establish effective links with local government and other sectors. The change agent can support direct training, exchange visits and other capacity building activities based on needs identified by the members of the community organizations. These can cover: organizational development, leadership, savings, and credits programmes, agriculture, natural resource management, and other key areas. Local human resource development can best be promoted when trained individuals take up the responsibility to train other community members [3].

Socio-economic development initiatives are a great incentive for community members to organize themselves. It is important, therefore, that initiatives, which include social mobilization, provide supports in the form of matching grants or access to credit, marketing and other services that will lead to tangible improvements in socio-economic conditions within the community. The process of identifying community priorities, participatory planning, implementing and monitoring of community projects and managing partnerships with local government, private sector and other actors helps not only to improve local conditions but also to empower people and their organizations [2]. In recent times, many grassroots micro movements also known as new social movements have been taking place centering on contemporary issues of importance such as ecology, environment, women empowerment, human rights, economic development, sharing of natural resources and the like. The NGOs in Pakistan have contributed handsomely towards social activism through intense campaigns, people's mobilization programmes and effective networks. The NGOs, as a social force facilitates collective action and people's mobilization. The NGOs play in making the people environmentally aware and sensitive to take part in the social activism through social mobilization process (Biswambhar Panda et. al., 2003). This study also highlights the role of the development organization in social mobilization process in the area of economic development.

\section{Introduction of the organization}

The human development foundation North America (HDFNA) was organized by a group of visionary Pakistani expatriates in 1997, with its headquarters in Chicago, USA. HDFNA's sister organization, human development foundation (HDF) Pakistan was created in 1999. The goal of HDF is to develop sustainable community development models, to transform lives through holistic approach of integrated programs. HDF works with its partner communities to help them achieve the millennium development goals (MDGs).

HDF has the vision to establish the tradition of philanthropy and volunteerism among the communities wherever they may be. Ultimately HDF envision is a global network which works towards the betterment and up lighting of underprivileged communities throughout the world. HDF holds the vision of communities which are prosperous, cohesive, vibrant and ready to face the challenges of unfolding Millennium. Such activities are only sustainable through communities support. To achieve these goals HDF uses the philosophy of distributed leadership and share responsibilities which encourage the voluntaries to be the leaders in their own sphere of activities. Working as a catalyst, HDF works with the communities, providing them with skills to manage their own affairs and implement an integrated community development program which includes community mobilization and social capital development, literacy and education, health and wellness, economic development and sustainable environment initiatives.

\section{Current activities of HDF}

The HDF is working on the targeted MGDs in the district Mardan, to promote gender equality and empowerment of women, reduce child mortality, improve maternal health, including reducing maternal mortality by three-quarters and prevent the spread of HIV/AIDS, malaria and other diseases. Presently the HDF is operating in 6 union councils (UCs) compromised of 81 villages, with the population of some about 65 thousand in district Mardan.

\section{Objectives}

The objectives of the internship report are as follow:

a. To study the work environment of development organization.

b. To know practically how an organization implement their plan and activities in the field.

c. To study the activities of Social Mobilization Programme of Human Development Foundation (HDF) in district Mardan.

\section{Review of Literature}

Literature review is important to identify the relevant research methodology and to specify correct analytical framework for the study in hand. Therefore a brief review of some relevant literature is given in the following section. [6] explored 
the management of natural resources through community participation. In the area of SUNGI Development foundation. The study highlighted the role of village committees in the adoption of improved seed and breeds, afforestation, reception of training, completion of productive village infrastructure schemes etc. The study revealed that the sense of responsibility and confidence has affected favorably the socio-economic standards of small farmers of the far-flung areas due to improvement in their agricultural production, livestock holdings, milk production and increase in plantation. True sustainable participation is possible only when the people are involved in identification, planning, implementation and evaluation of all development programs. More stress is requires in continuity of the work with increased community participation.

According to Gurumoorthy [7] empowering women contributes to social development. Economic progress in any country whether developed or underdeveloped could be achieved through social development. The Self Help Group disburses micro credit to the rural women for the purpose of making them enterprising women and encouraging them to enter into entrepreneurial activities.

Haqet [8] identified effective social mobilization approaches for service delivery in urban contexts of Pakistan. It was found that though there is a range of material which uses the term social mobilization and even focuses on Pakistan, much of this material does not relate to social mobilization for service delivery. Among the literature on social mobilization, including the literature specific to the country, a significant proportion focuses on rural contexts. Self-help groups were suggested as effective social mobilization approaches for service delivery in the country.

Idrees [1] examined the role of Sarhad Rural Support Program (SRSP) in gender development in rural villages of District Peshawar. For this, data were collected from 60 women respondents. Results revealed that the SRSP had introduced a number of interventions to mobilize women. Woman Community Organizations (WCOs) were established which were reported as the most primary source of motivation. Because of patriarchal nature of society; males, social workers, religious leaders and teachers were contacted to pave way for the formation of the WCOs. To accelerate social mobilization, the women community were sensitized through social organizers and interventions were designed and implemented that were based on societal needs. All these efforts mobilized the women to an extent where they started making decisions independently.

Israr \& Ahmad [9] identified the difficulties in the formation of village organizations in the social mobilization process of SUNGI Development Foundation. They found lack of awareness, cultural constraints, lack of capacity building and reluctance of the local people to the foundation in the area. To overcome the identified problems; creation of awareness by increase visits, trainings and allocation of more funds were suggested by the study.
Khan [10] studied the needs of village organizations of Agha Khan Rural Support Programme (AKRSP) in Pakistan. The identified needs in Gilgit, Chitral and Baltistan, were organization and collective management, land development, increased productivity, credit and banking, marketing, a reduction in the workload of women and coordination in the social sector. The study concluded that the success depends on the willingness of villagers to manage their affairs cooperatively, generate their own capital through savings and upgrade their human skills.

Khan [11] evaluated the effectiveness of participatory strategy in mobilizing community for utilizing the services of development project in the tribal and feudal structure of Nasirabad area of Balochistan. The major findings include that project has been partially successful in motivating the community towards exploiting the project resources while most of the community organizations remained unsuccessful. It was also found that the community organizations would not remain sustainable due to institutional and financial problems. Therefore, changes are needed in the participatory approach in the tribal structure of the study area.

Leach \& Scoones [12] explored the reasons of human mobilization based on a series of case studies. They identified a range of reasons which include; genetically-modified crops, vaccines, HIV/AIDS, occupational health, struggles around water, housing, labour rights and the environment. The authors concluded that mobilized citizens were knowledgeable actors engaged in dynamic and networked politics. They were also involved in shifting forms of social solidarity and identification at local, national and global levels.

Zulfiqar [13] examined the efforts made by AKRSP to foster the development of human resources, especially in the field of agriculture, livestock, forestry and enterprise development in Hunza Gilgit. It was found that a positive relationship exists between the trainings imparted by AKRSP in the area and production of vegetables, fruit and different cash crops. The units of livestock holding have been decreased with exception poultry. Diseases and mortality rate of animals have been also decreased significantly. The study concluded that the trainings imparted by AKRSP along the input use and the awareness created by AKRSP had positively contributed in agricultural, livestock, forestry and enterprise development as well as socio-economic development in the area. The AKRSP must extend their activities to other areas as well.

\section{Methodology}

Human Development Foundation started its Social Mobilization Programme in district Mardan, since 1999 among six union councils i.e. Mardan Rural, Chamtar, Khazana Dheri, Manga, Maho Dheri and Mohabad Abad. Social mobilization is to empower the community at gross root level or to create awareness among the local community, local institution and local leadership to identify their problems and suggest solution 
of the problems. Social mobilization requires full community support with active participation from local institution, leader's community groups and residents that work collaboratively towards common goal. The overall objective of the programme is to develop social capital and prepare the communities to undertake sustainable development initiatives [14].

\section{Approach towards the social mobilization program}

Participatory Rural Approach is a process or approach used by UDF for the social mobilization programme. The approach aims to incorporate the views, knowledge and opinions of rural peoples in planning and management of development projects and programs.

\section{Programme implementation}

Immersions phase: In the immersion phase HDF and community interact with each other in a way to understand each other. The immersion phase is divided into two steps i.e.; first contact and HDF introduction.

Initial/first contact: First contact means visiting the community for the first time to identify contact persons/activists of the area. Social organizer (SO) was responsible to make first contact. In the first contact HDF programme was introduced to the contact person or activist by describing its vision, mission, goals, and its working methodology etc. First contact may involve more than one visit. During the visits the SO identify and meet activists who are social worker, teacher, religious leader Nazim/Councilor or any other well reputed person within the community. During the visit basic information collected about the community and SWOT analysis held before HDF introduction.

HDF program introduction: At this stage corner/Mohalla/ Groups and general body meetings arranged where detail HDF introduction (HDF History, Mission, Vision, Goals, Programs working methodology, importance and need of VDO, structure of VDO) was made by using HDF introductory [15] charts. The objectives of social mobilization and concept of local institution development also shared with the community.

Formation of social institutions: Social institution process starts immediately after the immersion phase provided that the community expresses its willingness for entering into a partnership with HDF. The following structure formed under the Social Institution Model as per need of the area.

a. Village Development Organization (VDO) at village level.

b. Formation of Sub committees of VDO.

Details are the following.

a. Village development organization

Village Development Organization is an apex body/ Organization at village level that has the representation from all the classes, castes, segments, and areas of the village. It is a representative, equitable and accountable body of the village making constant efforts to actively undertake the development initiatives in collaboration with all the stakeholders [16].

\section{b. Functions of VDOs at village level}

a. To facilitate communities at village level in the formation of equitable and accountable organization for discussing, planning and implementing solutions to the problems.

b. To enable community to build its resources through communal fund, contribution/donations or from other sources for the initiation of projects on self help basis at village level.

c. To enable community at village level to demand services from the line agencies around them through linkages and development (Figure 1).

d. Structure of VDO:

HDF'S HODEL OF VILLAGE DEVELOPHENT ORGANIZATION

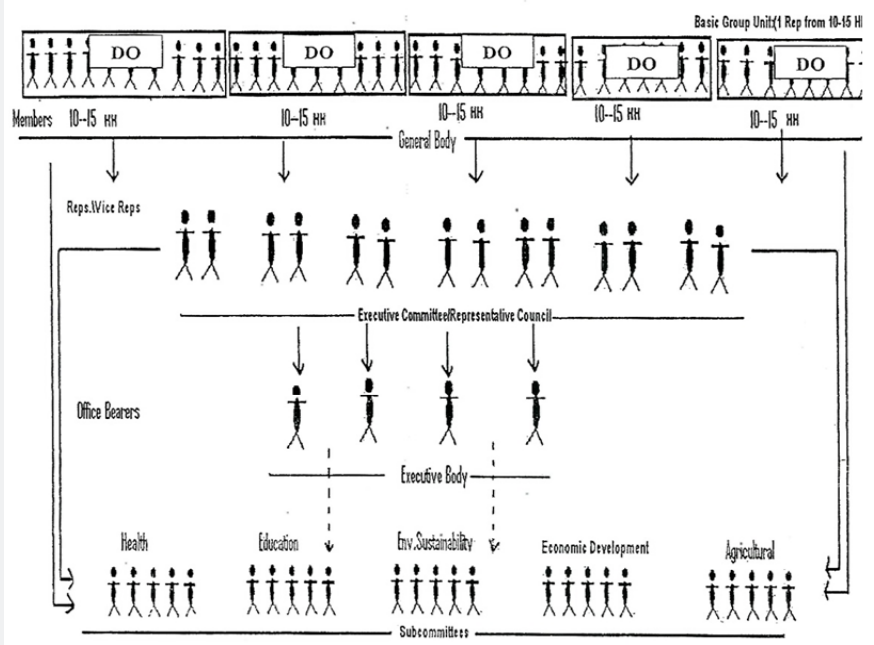

Figure 1: Structure of VDOs of Social Mobilization Programme. 


\section{Sub committees and its functions}

In each VDOs a subcommittee was formed to make the work more focus as it provides basic information and suggestion to VDOs for the solution of the problems. For example "Education committee" has the responsibility to find out the children that are out of school and present their names to VDOs to enroll these children in schools to ensure $100 \%$ enrollment in the village or for example a member of education committee of VDOs also member of PTC to present the budget and their use to VDOs to ensure the transparency.

\section{Future plan for VDOs}

HDF has the plan in the future to with drawl from those villages and union councils which have achieved "A" level grade. The A level grade of VDOs means that they are self-sustainable and at least $90 \%$ achievements in education, health, economic development and community physical infrastructure have been achieved. Moreover, they are capable to run the village activities on self-help basis.

\section{Finding and Discussions}

Human Development Foundation (HDF) has been fighting against extreme poverty and deprivation through a unique holistic model of development focused on lasting change. The core stone of HDF efforts is commitment to work directly with communities through the social mobilization program. Through this program, HDF facilitated the formation of democratic community organizations that empower individuals to have a say in the decisions that affect them. The working areas of the programme are education, health, economic development, community physical infrastructure and social capital. Since 1999, HDF through its Social Mobilization Programme is operating in 6 UCs which comprised of 81 villages of district Mardan. The estimated population of the area is about 65 thousand. Under the programme, a total of 79 VDOs are formed in the 79 villages of the district by PRA. Similarly, under each VDO a subcommittee was also formed to facilitate the process. At village level a VDO has the representatives from all the classes, castes, segments, and areas of the village. It is equitable and accountable body of the village along with its subcommittees, making constant efforts to actively undertake the development initiatives in collaboration with all the stakeholders. Out of 79 VDOs, 45 achieved grade " A " position, 9 achieved grade " $B$ " and 25 are in grade $C$. These grades are assigned to the VDOs on the basis of their performance in education, health, economic development, community physical infrastructure and social capital formation. During the course of internship, I was involved in different activities of the Programme as an internee. I was actively involved in the assessment phase of three villages namely Shahi Bagh, Khazana Dheri and Shah Kaly).

These villages; Shahi Bagh, Khazana Dheri and Shah Kaly acquired grades A, B and C respectively in the assessment. HDF is working since long from 1999 in the district through its Social Mobilization programme, but did not achieved the required results in most of the villages due to multiple constraints. During my internship, I observe that there are 79 villages in the district in which HDF are working but the organization had only three male and one female social organizer. All the village level activities are carried out by these personnel, which burdened them and affect the quality of the work. The VDOs were not working properly due to multiple constraints. One of the major constraint was that people in villages either work on farms or have jobs where there is hardly a day off. Thus they are not able to find enough time for community problems because they were contacted at their working hours. Secondly, there was low female participation in VDOs which was attributed to Pukhtoon culture, where women are prohibited to participate in the village development activities which also effect the achievement of programme objectives. As HDF lack sufficient female staff so it made the situation more critical. During the internship it was also observed that community consider developmental activities like street pavement, latrines or other tangible work valuable, while the Social Mobilization programme work through change in people' attitudes and change in the social structure or social order of the society, which leads to sustainable development. This is the area where the organization and community interest clash with each other. It results in the shape of lack of interest of the community which also effect HDF efforts for sustainable development. It shows the HDF staff in capabilities, which did not make a change in people minds. During internship, a total of four medical camps were arranged by HDF. I actively participated in the entire arrangement process. Furthermore, I also contributed in the arrangement of an inter school competition "Youth Sports Festival" in district Mardan, which aimed to engage the youth in healthy activities [17].

\section{Summary}

This internship report was conducted with the objectives to study the work environment of development organizations and the activities of Social Mobilization Programme in district Mardan of Khyber Pakhtunkhwa. The HDF started its Social Mobilization Programme in six union councils i.e. Chamtar, Khazana Dheri, Manga, Maho Dheri and Mohabad Abad of the district since 1999. The aim of the programme is to empower the community at gross root level or to create awareness among the local community, local institution and local leadership to identify their problems and suggest solutions of the problems. Social Mobilization requires full community support with active participation from local institution, leader's community group and residents that work collaboratively towards common goal. The objective of the Social Mobilization is to develop social capital and prepare the communities to undertake sustainable development initiatives. The methodology for Social Mobilization which was used by HDF is Participatory Rural Approach (PRA). This approach aims to incorporate the views, knowledge and opinions of rural peoples in planning and management of development projects and programs. Through this approach the Social Mobilization Team makes the Village Development Organizations (VDOs) at village 
level which has the representatives from all the classes, castes, segments, and areas of the village. It is equitable and accountable body of the village along with its subcommittees, making constant efforts to actively undertake the development initiatives in collaboration with all the stakeholders. The main findings of HDF through its programme are that in 79 villages VDOs were formed along with subcommittees. Out of 79 VDOs, 45 are in grade "A", 9 in grade "B" and 25 are in grade "C". These grades are assigned to them due to the maturity levels of a VDO which are given to them on their performance including education, health, economic development, community physical infrastructure and social capital. The programme is operating since long in the district, but did not achieve the sufficient required results due to some constraints which were observed in the internship period [18]. The constraints were; insufficient male and female staff, Pahtun culture and community perceptions about tangible work.

\section{Conclusion}

The findings of the report concluded that HDF is working through its Social Mobilization Programme in six UCs (i.e.; 79 villages) of district Mardan since 1999. Social Mobilization is a leading way to community development. It helps to organize and mobilize the communities to enhance their capacities. It promotes people participation in the process of development, and sensitizes them to make collective efforts to influence the system through its VDOs and sub committees' structure. HDF is striving hard to achieve programme objectives, by engaging the communities in programme interventions. Out of 79 VDOs, 45 achieved grade "A", 9 grade "B" and 25 grade " $C$ ". The programme is operating since long in the district, but did not achieve the sufficient required results due to some constraints which were observed in the internship period. The constraints were; insufficient male and female staff, Pashtun culture and community perceptions about tangible work.

\section{Recommendations}

On the basis of the internship report the following recommendations are enlisted.

a. There is a need for the hiring of technical and qualified staff for smooth running of the programme achievement at the field.

b. There must be a proper arrangement of training and different seminars for the improvement of employees' skills for the successful process of social mobilization.

c. Field visits must be arranged at convenient venues and timings with respect to community people.

\section{References}

1. Idress M, Jadoon MA, Bibi S, Mahmood Z (2008) Factors affecting the mobilization of rural women through sarhad rural support program (SRSP) in district Peshawar. Sarhad J Agric 24(1): 155-160.

2. Prasad (2003) Social mobilization: Concept, meaning and approach (Part-1). Kurukshetra 51(8).

3. Villi D (2008) The role of NGOs in social mobilizations in the context of SGSY. State institute of rural development Maraimalai Nagar.

4. UNICEF (2007) Social mobilization; An effective tool for community development.

5. Rana (2001) Women's groups herald a wind change in rural Uttaranchal. Kurukshetra Social Action 53.

6. Ayaz M (2010) The role of SUNGI development foundation in the management of national resources through community participation; A case study selected villages in district Haripur. Unpublished M.Sc. (Hons) Thesis. Institute of Development Studies The University of Agriculture Peshawar, Pakistan.

7. Gurumoorthy TR (2000) Self-help groups empower rural women. Kurushetra 48(5): 36-39.

8. Hussain H (2012) The Role of Agha Khan Support Programme in agricultural and livestock production in District Diamer, A case study of three selected villages in Tehsil Astore, Institute of Development Studies, KPK Agricultural University Peshawar Pakistan.

9. Israr, Ahmad (2009) Village organization activities for rural development in North West Pakistan. Sarhad J Agric 25(4): 641-648.

10. Khan AR (2007) Community mobilization through participatory approach; A critical assessment. Pak Eco Soc Review 44(2): 245-258.

11. Khan AR (2006) Community mobilization through participatory approach; A critical assessment. Pak Eco Soc Review 44(2): 245-258.

12. Leach M, Scoones I (2008) Mobilizing citizens: Social movements and the politics of knowledge. IDS Working Paper No. 276. Brighton: Institute of Development Studies.

13.Zulfiqar AK (2011) The Role of Agha Khan Support Programme in human resource development in Northern Areas; A case study of three selected villages in sub division of Hunza, Gilgit M.sc (Hons.) Thesis Institute Development Studies, The University of Agriculture Peshawar, Pakistan.

14. Haq Z, Khan W, Rizwan S (2013) Advocacy, communication and social mobilization for tuberculosis control in Pakistan: A qualitative case study. Int J Tuberc Lung Dis 17(3): 394-399.

15. Jabbar A (2009) Role of Agha Khan Rural Support Programme in Agricultural Development in North Areas; M.sc (Hons.) Thesis, Department of Agriculture Economics and Rural Sociology, Khyber Pakhtunkhwa Agricultural University Peshawar Pakistan.

16. Omolo EO, Ssennyonga JW, Ngugi A, Kiros F, Okali C (2010) Community mapping exercises: an evaluation. Network paper Agricultural Admnistration Research and network extension 13: 24-55.

17. Shah A (2012) The role of (AKRSP) to promote community participation in natural resource management. Sarhad J Agri 5(7): 68-70.

18. Staniland P (2010) Cities on fire: social mobilization, state policy, and urban insurgency. Comparative Political Studies. 43(12): 1623-1649. 
This work is licensed under Creative Commons Attribution 4.0 Licens DOI: 10.19080/GJIDD.2018.04.555631
Your next submission with Juniper Publishers will reach you the below assets

- Quality Editorial service

- Swift Peer Review

- Reprints availability

- E-prints Service

- Manuscript Podcast for convenient understanding

- Global attainment for your research

- Manuscript accessibility in different formats ( Pdf, E-pub, Full Text, Audio)

- Unceasing customer service

Track the below URL for one-step submission https://juniperpublishers.com/online-submission.php 